\title{
Immunolocalization of Nucleolar Proteins after D-Galactosamine-Induced Inhibition of Transcription in Rat Hepatocytes
}

\author{
Maintenance of Association of RNA Polymerase I with \\ Inactivated Nucleolar Chromatin
}

\author{
KRASSIMIRA HADJIOLOVA, ${ }^{1, *}$ KATHLEEN M. ROSE ${ }^{2}$ \\ and ULRICH SCHEER ${ }^{1}$ \\ ${ }^{1}$ Division of Membrane Biology and Biochemistry, Institute of Cell and Tumor Biology, \\ German Cancer Research Center, D-6900 Heidelberg, FRG, and ${ }^{2}$ Department of \\ Pharmacology, Medical School, University of Texas, Houston, TX 77225, USA
}

\begin{abstract}
The fate of defined nucleolar constituents during D-galactosamine-induced inhibition of transcription and the accompanying extensive structural changes such as nucleolar segregation, fragmentation and disappearance of the granular components was studied by light and electron microscopic immunolocalization, using antibodies to different nucleolar components. In contrast to other inhibitors such as actinomycin $\mathrm{D}$, we show that preribosomal components as monitored by a ribosomal protein leave the nucleolus, while a large proportion of RNA polymerase I remains associated with the nucleolar chromatin, i.e. probably the pre-rRNA genes, during inactivation of transcription. These small structures containing the RNA polymerase I are characterized by low electron density and resemble the 'fibrillar centers' of normal nucleoli. The results are discussed in relation to current concepts of the functional topology of the nucleolus. (c) 1986 Academic Press, Inc.
\end{abstract}

The selective interaction of RNA polymerase I with the genes coding for ribosomal RNA (rRNA) plays a central role in the transcriptional control of ribosome biogenesis in eukaryotes (for reviews, see [1, 2]). The transcriptionally active rRNA genes are located in the nucleolus, and elucidation of the intranucleolar topology of their individual components such as rDNA, RNA polymerase I and growing ribonucleoprotein fibrils containing nascent pre-rRNA is important for an understanding of the functional organization of the nucleolus (for review, see [3]). Visualization of transcription complexes by chromatin spreading has provided a detailed picture of the molecular organization of transcriptionally active rRNA genes from a wide variety of species ([4]; for reviews, see [5-9]). However, the intranucleolar location of these structures in situ is still a matter of debate. From biochemical and autoradiographic studies on the localization of short-term labeled pre-rRNA it has been suggested that transcription takes place within-or at the border of-the dense fibrillar component of nucleoli $[1,3$,

\footnotetext{
* Permanent address: Institute of Molecular Biology, Bulgarian Academy of Sciences, 1113 Sofia, Bulgaria.
} 
10-12]. In contrast, recent immunolocalization of RNA polymerase I in regenerating rat liver and hepatoma cells revealed this enzyme to be mainly, if not exclusively, in the fibrillar centers of nucleoli, indicating that transcription of rDNA occurs within this specific nucleolar component [13].

To clarify further the in situ location of template-engaged polymerase I molecules we have used several transcription inhibitors that induce extensive alterations of nucleolar architecture. For instance, exposure of cultured cells to the adenosine analogue, 5,6-dichloro-1- $\beta$-D-ribofuranosylbenzimidazole (DRB) which leads to reversible unravelling of the normally compact nucleoli, without inhibition of rDNA transcription [14, 15], results in the dispersion of nucleolar components. The nucleolar 'necklaces' that are formed retain RNA polymerase I, but not the precursor particles to the small ribosomal subunit [16]. On the other hand, prolonged inhibition of transcription with actinomycin $\mathrm{D}$ (AMD) resulted in a marked decrease of nucleolar RNA polymerase I [13]. However, as this DNAintercalating drug induces the premature release of transcriptional complexes from the rDNA-containing chromatin $[17,18]$, the study of transcription inhibitors which do not interact with rDNA would be of particular interest.

In this respect the action of D-galactosamine on rat hepatocytes constitutes a very valuable tool (for reviews, see [1, 19, 20]). Administration of D-galactosamine to rats has a powerful 'trapping effect' on free uridine nucleotides, resulting in the formation of large amounts of UDP-hexosamines, thereby reducing the intracellular UTP pool of hepatocytes to background levels within 15-30 min [21-23]. Depletion of the intrahepatic UTP pool results in a general inhibition of RNA synthesis [22, 23-25]. Under these conditions pre-existing $45 \mathrm{~S}$ pre-rRNA is continued to be processed to nucleolar $28 \mathrm{~S}$ and $18 \mathrm{~S}$ rRNA and transported into the cytoplasm [22-25].

These biochemical changes are accompanied by an extensive loss of structures of granular components ('degranulation') of the nucleoli, concomitant with nucleolar fragmentation and segregation into smaller subnucleolar structures ("microsegregation'; [26]). Within $2 \mathrm{~h}$ the volume of the granular component of nucleoli is markedly reduced, whereas the fibrillar component is greatly condensed, so that only fibrillar remnants associated with some spherical bodies are left $[24,26]$. Following $4 \mathrm{~h}$ of drug action the latter structures then collapse, leaving behind solely the dense fibrillar remnants [26]. Particle isolation studies and biochemical analysis have shown that these residual structures are almost totally devoid of rRNA precursor molecules but that they retain the bulk of the rRNA genes and several nucleolar proteins [27].

With the availability of various antibodies to different nucleolar components it is now possible to follow the fate of defined nucleolar constituents during the structural changes induced by D-galactosamine by light and electron microscopic immunolocalization techniques. In the present study we report on the redistribution of representative nucleolar constituents of the three main components of rat hepatocyte nucleoli; these are RNA polymerase I, a representative ribosomal 
protein (S1), and a protein located in the dense fibrillar component of nucleoli. We show that the intimate association between fibrillar centers and the dense fibrillar component is preserved upon D-galactosamine-induced nucleolar fragmentation and that RNA polymerase I remains bound to special satellite bodies located in the periphery of the dense fibrillar remnants. Our results demonstrate that the changes in the organization of the transcriptional components of the nucleolus that are observed after galactosamine treatment are radically different from those observed upon action of other inhibitory drugs such as DRB and $\mathrm{AMD}$ and that the association of some RNA polymerase I with the nucleolar chromatin is not dependent on the continuation of pre-rRNA synthesis.

\section{MATERIALS AND METHODS}

\section{Biological Material}

The experiments were carried out with female albino rats weighing $110 \pm 10 \mathrm{~g}$. D-Galactosamine hydrochloride (Serva, Heidelberg, FRG) in $0.14 \mathrm{M} \mathrm{NaCl}$ was administered intraperitoneally at a dose of $250 \mathrm{mg} / \mathrm{kg}$ body weight. 30, 60, 120 and $240 \mathrm{~min}$ after drug administration animals were killed by cervical dislocation. Livers were immediately removed and small pieces were quick-frozen in isopentane cooled with liquid nitrogen.

\section{Antibodies}

Antibodies raised in rabbits against purified RNA polymerase I from a rat hepatoma have been characterized $[13,28]$. The immunoglobulin fraction obtained by ammonium sulfate precipitation was used at a concentration of $50 \mu \mathrm{g} / \mathrm{ml}$. Monoclonal antibodies ( $\mathrm{IgM}$ ) to ribosomal protein S1 of the small ribosomal subunit [29] were used as hybridoma cell culture supernatant without further dilution. Monoclonal antibody $72 \mathrm{~B} 9$ (IgG) was obtained from Dr E. Tan's laboratory (Scripps Clinic and Research Foundation, La Jolla, Calif.).

\section{Immunofluorescence Microscopy}

Cryostat sections $5 \mu \mathrm{m}$ thick were air-dried on microscope slides and dehydrated in acetone for 10 $\min$ at $-20^{\circ} \mathrm{C}$. After incubation with the first antibodies for $20 \mathrm{~min}$ at room temperature, the specimens were washed several times with phosphate-buffered saline (PBS). Fluorescein isothiocyanate-conjugated secondary antibodies (FITC goat anti-mouse Ig; FITC goat anti-rabbit IgG; from BioYeda, Rehovot, Israel, or from Dianova, Hamburg, FRG) were used at a dilution of $1: 20$ (in PBS) for $20 \mathrm{~min}$. After several washes in PBS, slides were dipped in ethanol, air-dried and the sections were embedded in Mowiol (Hoechst, Frankfurt, FRG). Photographs were taken with a Zeiss Photomicroscope III equipped with epifluorescence optics (Carl Zeiss, Oberkochen, FRG).

\section{Electron Microscopic Immunolocalization}

The pre-embedding labeling technique of cryosections used in this study was as previously described $[13,29]$. Bound antibodies were detected by secondary antibodies coupled to 5 -nm gold particles (from Janssen Life Sciences, Beerse, Belgium). A Siemens Elmiskop 101 and a Zeiss electron microscope EM 10 were used for examination.

\section{RESULTS}

\section{Immunofluorescence Microscopy}

In normal rat hepatocytes antibodies to RNA polymerase I bound exclusively to the nucleoli (fig. $1 a, b$ ), as previously described [13]. Two hours after D- 
484 Hadjiolova, Rose and Scheer

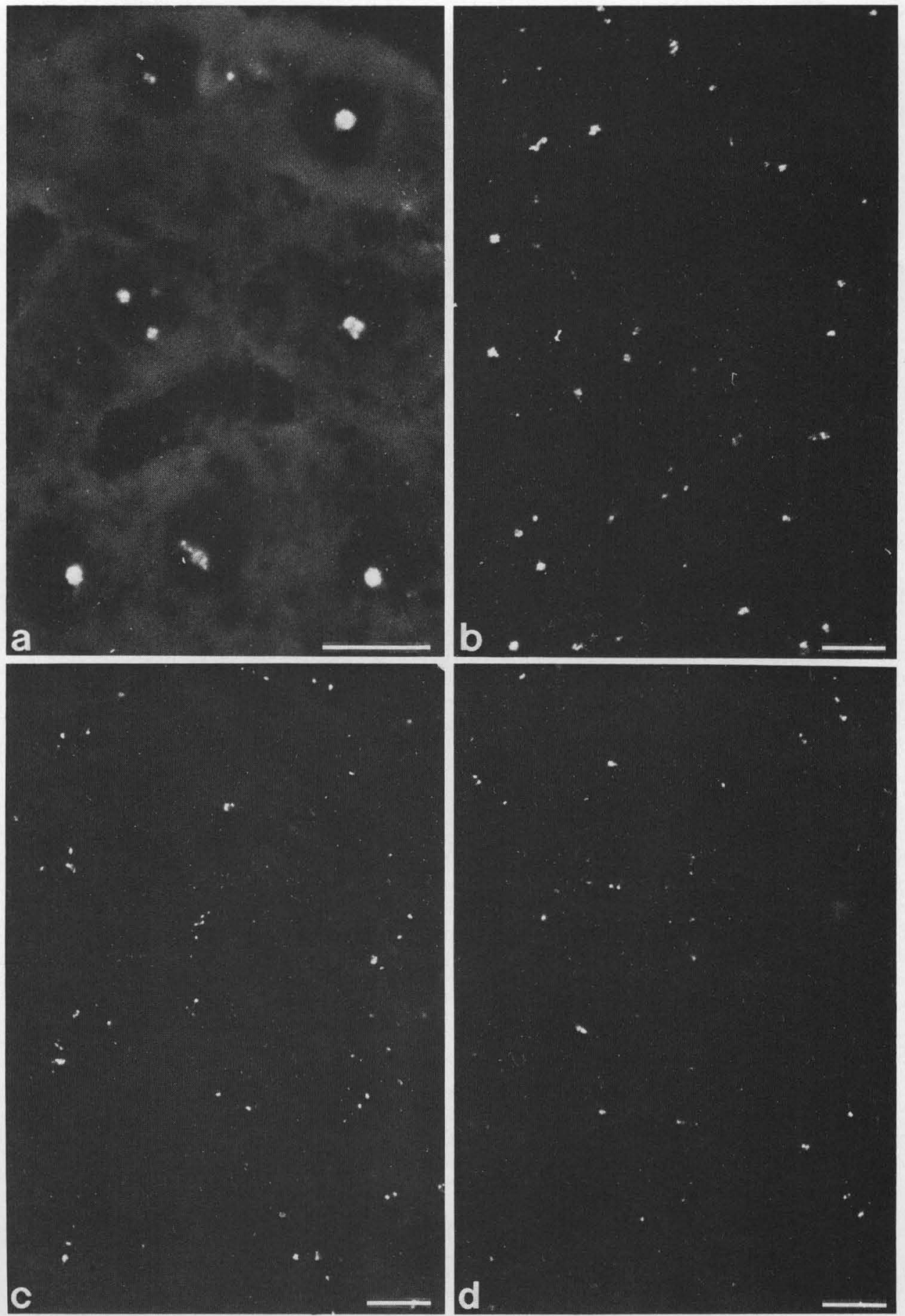




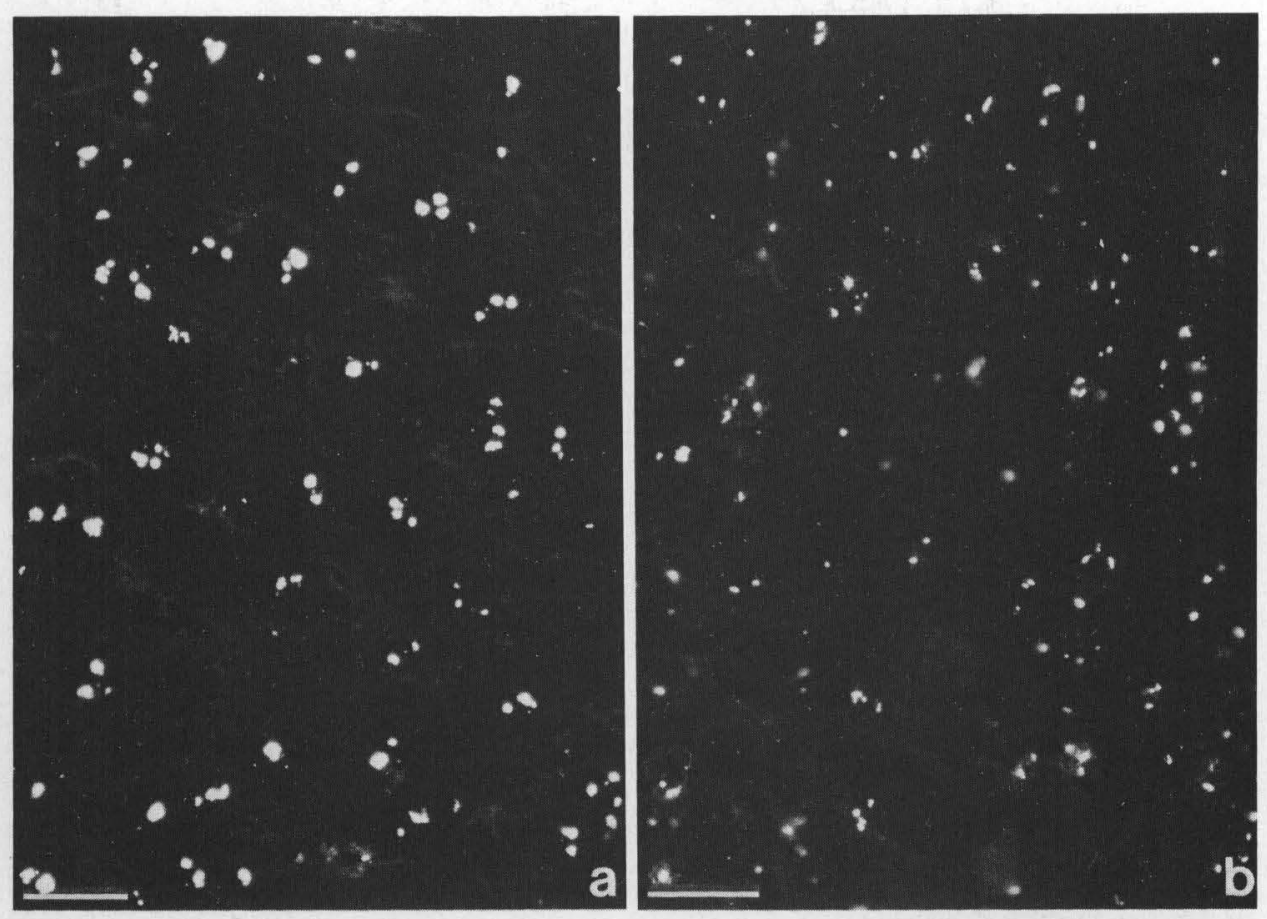

Fig. 2. Immunofluorescence microscopy of monoclonal antibody $72 \mathrm{~B} 9$ which reacts preferentially with the dense fibrillar component of nucleoli. Frozen sections of $(a)$ untreated rat liver; $(b)$ after $4 \mathrm{~h}$ of D-galactosamine treatment. Bar, $20 \mu \mathrm{m}$.

galactosamine treatment the sizes of the RNA polymerase I-positive structures were markedly reduced, whereas their number appeared to be increased in numerous cell nuclei, suggesting that extensive fragmentation of the nucleoli into smaller subcomponents had taken place (fig. 1c). The fluorescence pattern remained essentially unchanged for up to $4 \mathrm{~h}$ after administration of D-galactosamine (fig. $1 d$ ), a point of time at which practically all nucleoli are known to be reduced to dense fibrillar remnants (cf $[26,30]$ ).

With monoclonal antibody $72 \mathrm{~B} 9$, which preferentially binds to the dense fibrillar region of normal nucleoli, no striking differences were noted between control preparations and liver from animals treated for $4 \mathrm{~h}$ with D-galactosamine (fig. $2 a$, $b$ ), except that the fluorescence-positive structures appeared to be somewhat reduced in size.

Fig. 1. Immunofluorescence microscopy on frozen sections of rat liver after incubation with antibodies to RNA polymerase I. Nucleoli of untreated liver are brightly fluorescing $(a, b$; their selective fluorescence is especially clearly seen at the higher magnification in $a)$. D-Galactosamine treatment $(c$, $2 \mathrm{~h} ; d, 4 \mathrm{~h}$ ) induces the nucleoli to fragment into several smaller though still fluorescing entities. Bar, $10 \mu \mathrm{m}$. 

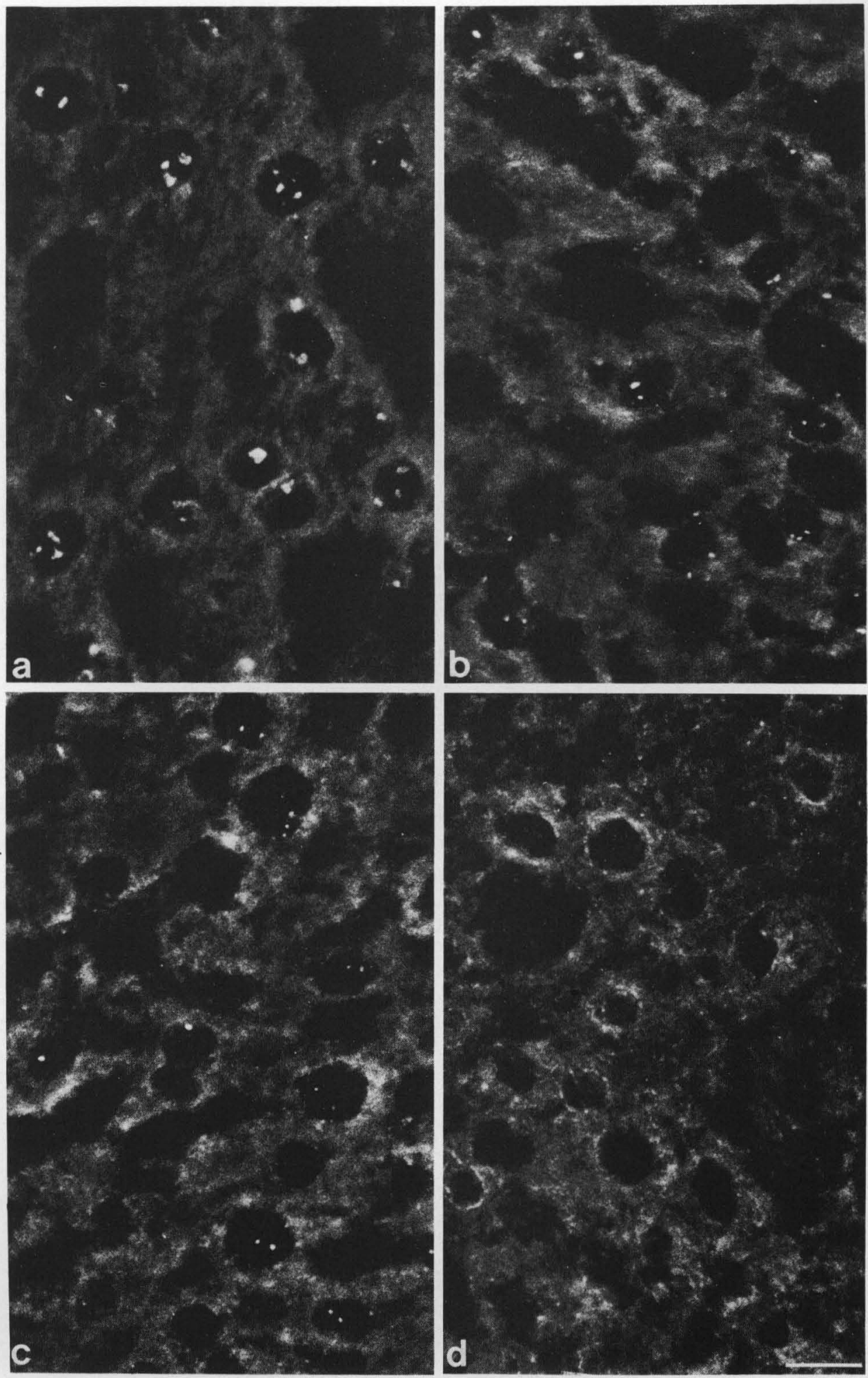
Fluorescence of hepatocyte nucleoli after incubation with antibodies to ribosomal protein S1 which stains the granular component of normal nucleoli [29], was drastically reduced upon treatment of rats with D-galactosamine (fig. $3 a-d$ ). In nuclei of rats treated for $4 \mathrm{~h}$ with $\mathrm{D}$-galactosamine nucleolar fluorescence was no longer detected (fig. $3 d$ ). In contrast, the cytoplasmic fluorescence, reflecting the binding of antibodies to ribosomes, remained unchanged (fig. $3 a-d$ ).

\section{Immunoelectron Microscopy}

In order to determine the location of RNA polymerase I with greater precision, we studied the binding of antibodies to polymerase I at the electronmicroscopic level by using secondary antibodies tagged with colloidal gold particles. In hepatocytes of control rats, gold particles were seen to be concentrated over roundish areas of relatively low electron density, the fibrillar centers, and were absent from the surrounding dense fibrillar and granular components (fig. 4), thus confirming our previous report [13]. After $2 \mathrm{~h}$ of D-galactosamine treatment the nucleoli were reduced to large blocks of densely packed fibrillar remnants in association with one or a few spheroidal bodies with a coarsely granular substructure (figs $5,6 a$ ). Gold particles indicating the distribution of RNA polymerase I were found mostly in clusters in the vicinity of the dense fibrillar remnants, but also in some small scattered nucleoplasmic units (fig. 5). Higher magnification clearly revealed that the gold particles in the nucleolar remnant structures were bound to a structural component of low electron density which differed morphologically from both the fibrillar remnant and the spherical body and resembled the fibrillar centers of normal nucleoli (fig. $6 a, b$ ). By $4 \mathrm{~h}$ of D-galactosamine block of transcription, all nucleoli were reduced to dense fibrillar structures which were attached to somewhat larger spheroidal bodies (fig. $6 c$ ). At this stage the aggregates of gold particles were found in distinct (though not very electron-dense) regions at the periphery of the fibrillar remnants but were virtually absent from all other nucleolar structures.

The striking resemblance of the gold-labeled regions surrounding the dense fibrillar remnants to the polymerase I-positive material constituting the fibrillar centers of normal nucleoli (compare fig. $6 a-c$ with fig. 4) indicates that these structures are equivalent. Apparently during nucleolar fragmentation the fibrillar centers break up into numerous smaller entities which, however, remain closely associated with the dense fibrillar component.

By means of the same immuno-gold technique, antibodies to ribosomal protein S1 did not show any significant signal in hepatocyte nuclei of galactosaminetreated rats, thus confirming the results obtained by immunofluorescence micro-

Fig. 3. Immunofluorescence microscopy of ribosomal protein $\mathrm{S} 1$ on frozen sections of rat liver (a) without; $(b)$ after $1 ;(c) 2$; and $(d) 4$ h of D-galactosamine treatment. Nucleolar fluorescence gradually diminishes, whereas the cytoplasmic fluorescence is still intense. Bar, $10 \mu \mathrm{m}$. 


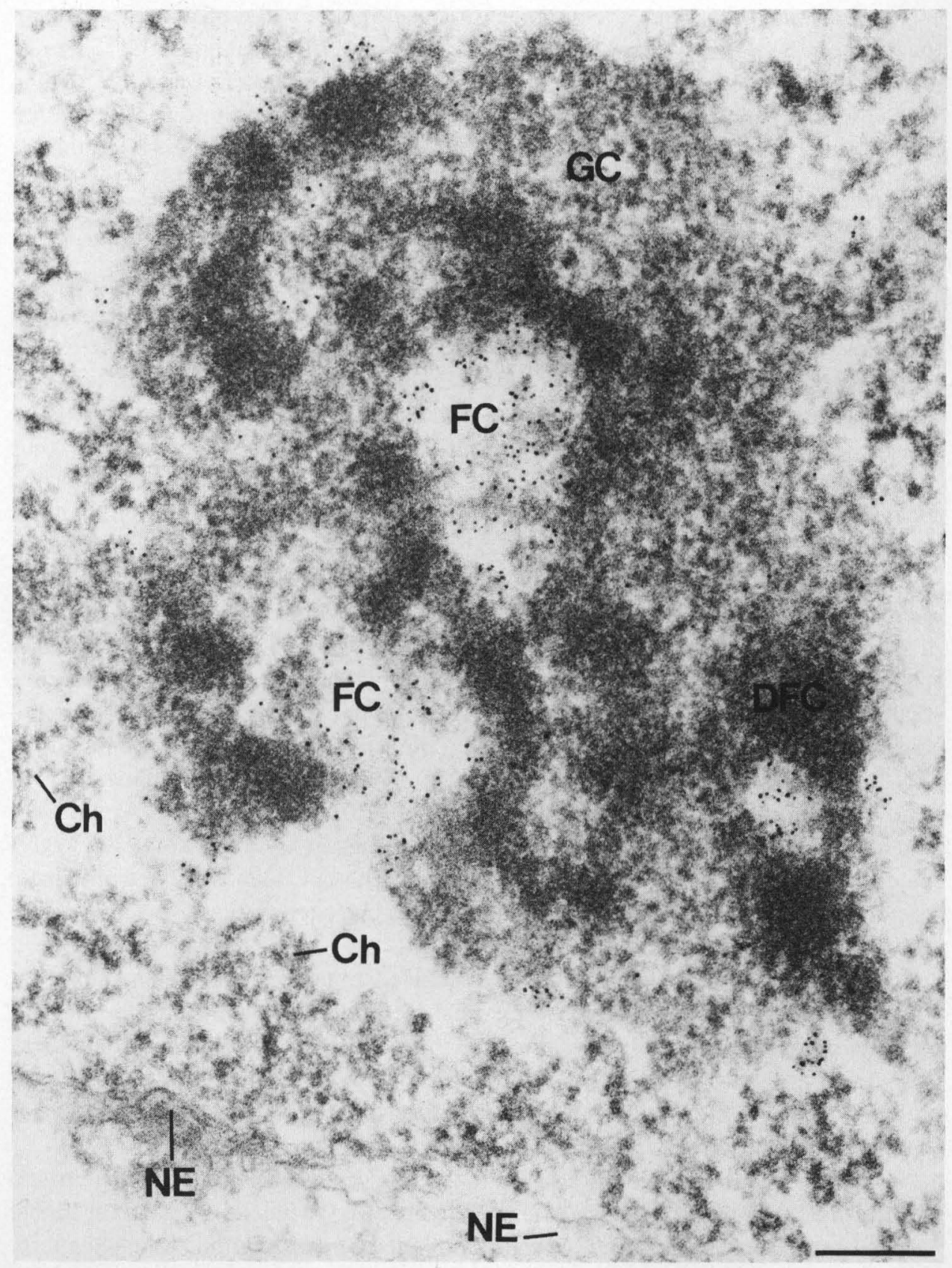

Fig. 4. Electronmicroscopic immuno-gold labeling of RNA polymerase I in hepatocyte nucleolus of untreated rat liver. The fibrillar centers $(F C)$ are specifically labeled, whereas the dense fibrillar component $(D F C)$, the granular component $(G C)$ as well as the surrounding chromatin $(C h)$ are almost free of gold particles. $N E$, Nuclear envelope. Bar, $0.2 \mu \mathrm{m}$. 


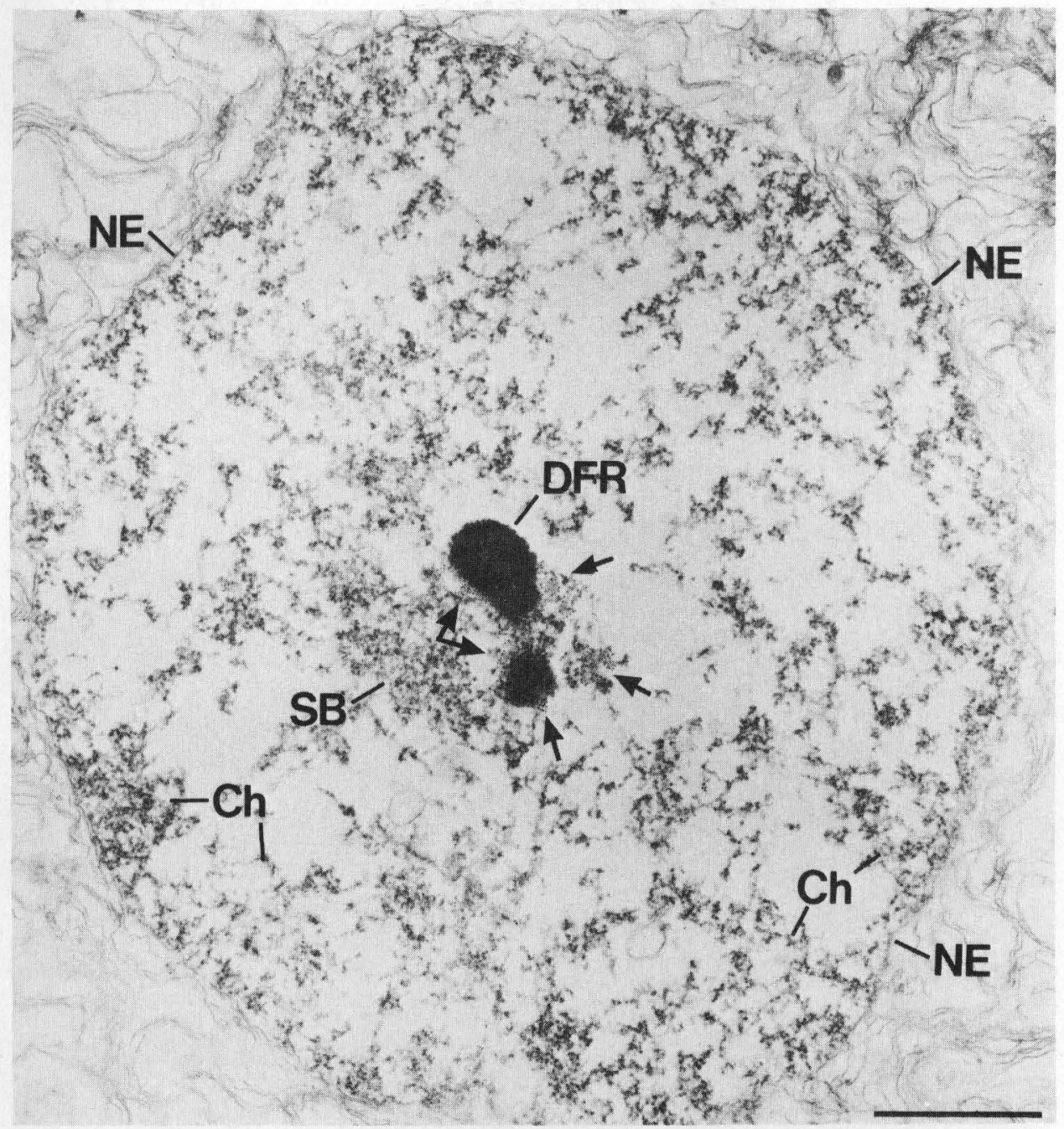

Fig. 5. Survey electron micrograph presenting the immunolocalization of RNA polymerase $\mathrm{I}$ in the nucleus of a rat hepatocyte at $2 \mathrm{~h}$ of $\mathrm{D}$-galactosamine treatment. The dense fibrillar remnant $(D F R)$ is surrounded by fragments of the fibrillar centers which are specifically labeled by gold particles (arrows). SB, Spherical body; $C h$, chromatin; $N E$, nuclear envelope. Bar, $1 \mu \mathrm{m}$.

scopy. In contrast, antibodies $72 \mathrm{~B} 9$ selectively decorated the dense fibrillar remnants, especially their outer zones (data not shown). None of the antibodies examined was localized to the so-called 'spherical bodies'.

\section{DISCUSSION}

The rapid cessation of RNA synthesis in rat hepatocytes following administration of D-galactosamine is believed to result from the depletion of intracellular 


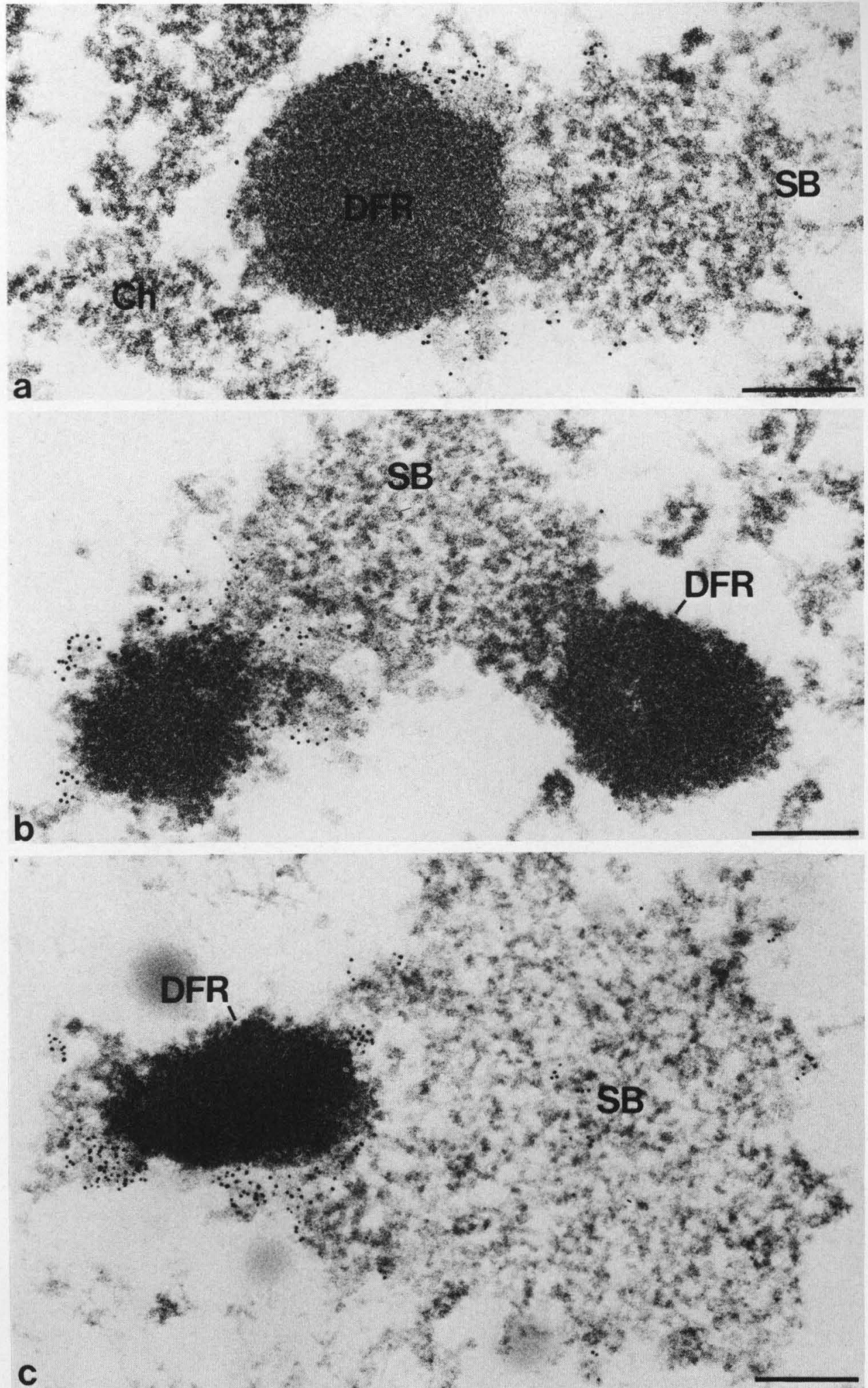


free UTP below a critical level (for references, see Introduction). Under these inhibitory conditions the pre-existing pre-rRNA molecules are processed to $28 \mathrm{~S}$ and $18 \mathrm{~S}$ rRNA and the pre-ribosomal particles are transported into the cytoplasm. Hence, the striking morphological changes in nucleoli observed after galactosamine administration may be directly related to a gradual depletion of the nucleoli from ribosomal precursor molecules and particles. In agreement with this interpretation is the present finding of a gradual disappearance of antigens reactive with antibodies to ribosomal protein $\mathrm{S} 1$ from the nucleolus and nucleus.

Our results also allow a better definition of the residual nucleolus-derived structures observed following galactosamine treatment, which appear to be the product of nucleolar fragmentation and 'microsegregation'. Both the very high electron density and the positive staining with antibody 72B9 support the notion that the dense bodies described as "dense fibrillar remnants" are indeed related to the dense fibrillar component of the normal nucleolus. (i) The absence of detectable amounts of RNA in the fibrillar nucleolar remnants [27, 31]; (ii) our present results that RNA polymerase I-associated nucleolar chromatin is confined to distinct weakly stained satellite structures located at the periphery of and not within the dense fibrillar material; and (iii) the lack of binding of DNA antibodies to these structures [36] all indicate that the morphological equivalent of transcriptionally inactivated rRNA genes is not represented by fibrillar remnant structures as a whole [26, 27], but only by the satellite structures associated with them. The data are compatible with the proposal that the bulk of the dense fibrillar material is of a purely proteinaceous nature (cf [32]). Recently a protein with a $M_{r} 180000$ has been identified in oocytes and in somatic cells of Xenopus laevis which is specifically confined to the dense fibrillar component of nucleoli, independent of their transcriptional activity [32].

Quite unexpected was our finding that a considerable proportion of polymerase I molecules remained bound to distinct, weakly stained small satellite bodies associated with the periphery of the fibrillar nucleolar remnants (this study, and ref. [13]). The electronmicroscopic immunolocalization data show that the structures containing this protein, and probably also its specific rDNA template, are very similar to the 'fibrillar centers' of normal nucleoli. Therefore, we conclude that both structures, the fibrillar centers and the satellite bodies associated with the fibrillar remnant bodies, are related and probably identical. We propose that condensation of the dense fibrillar component during galactosamine treatment results in a topological reorganization in such a way that the fibrillar centers containing the rRNA genes are no longer embedded in and surrounded by the

Fig. 6. Electronmicroscopic immunolocalization of RNA polymerase I in fragmented nucleoli of rat hepatocytes after $(a, b) 2 \mathrm{~h},(c) 4 \mathrm{~h}$ of D-galactosamine treatment. The dense fibrillar remnant bodies $(D F R)$ are in intimate contact with loosely structured spherical bodies $(S B)$. Aggregates of gold particles are selectively bound to diffusely stained material which is located along the periphery of the dense fibrillar remnants. $C h$, Chromatin. Bar, $0.2 \mu \mathrm{m}$. 
dense fibrillar components but distributed into smaller entities which, however, remains associated with the periphery of the fibrillar remnant structures.

Perhaps the most surprising observation is our immunolocalization finding that the structural changes of inactivated nucleolar chromatin are different in different forms of inhibition. The DNA intercalating drug AMD causes the disappearance of RNA polymerase I from the nucleolar residue structures [13], apparently concomitant with a progressive release of nascent pre-rRNA chains and their transcriptional complexes $[17,18]$. In contrast, the persistent association of RNA polyermase I molecules with the rRNA genes during transcriptional inactivation by galactosamine treatment resembles the behaviour of this protein during mitosis, a natural stage of transient inactivation of genes, including rRNA genes, during which polymerase I remains bound to the nucleolus organizer regions (NOR) of metaphase chromosomes [13]. In mitosis, this persistent structural association between rRNA genes and RNA polymerase I might be necessary to ensure a rapid resumption of transcriptional activity at the end of telophase. Similarly, the galactosamine-induced block of transcription is also rapidly reversible by administration of uridine to galactosamine-intoxicated rats [24]. At present we cannot decide whether this maintenance of association of RNA polymerase I molecules with nucleolar chromatin is really due to the binding of this protein in the complete absence of transcription or whether it reflects some low level transcription which does not lead to stable pre-rRNA molecules.

On the D-galactosamine-induced disappearance of preribosomal particles from the typical granular component of the nucleolus ('degranulation', cf ref. [26]) and the condensation of the fibrillar component, a meshwork structure is exposed in the residual nucleoli ('spherical body') which is not recognized in nucleoli of untreated rat liver. It has been suggested that this spherical body represents some kind of an underlying scaffold or matrix component which provides structural support for the attachment of preribosomal particles [26, 27]. Our present results support this view as they show that neither of the antibodies directed against the three 'classical' nucleolar components reacts with these bodies. Probably this fourth nucleolar component corresponds to the high-salt buffer- and detergentresistant nucleolar protein skeleton which, in Xenopus laevis, has been shown to contain a major protein of $M_{r} 145000$ [33-35]. Experiments aiming at the elucidation of this fourth component are underway.

We are grateful to Dr B. Hügle (this institution) for gifts of monoclonal antibody RS1-105 (anti S1) and to Drs G. Reimer and E. Tan (Scripps Clinic, La Jolla, Calif.) for monoclonal antibody 72B9. We thank Dr W. W. Franke for many helpful discussions and for reading and correcting the manuscript. The work received financial support from the Deutsche Forschungsgemeinschaft (Sche 157/5-4 and the USPHS grant GM 33442 given to K. M. R.).

\section{REFERENCES}

1. Hadjiolov, A A, The nucleolus and ribosome biogenesis. Cell biology monographs, vol. 12 . Springer-Verlag, Wien, New York (1985). 
2. Rose, K M, Stetler, D A \& Jacob, S T, Enzymes of nucleic acid synthesis and modification, vol. 2 RNA enzymes (ed S T Jacob) p. 43. CRC Press, Boca Raton, Fla. (1983).

3. Goessens, G, Int rev cytol 87 (1984) 107.

4. Miller, O L \& Beatty, B R, Science 164 (1969) 955.

5. Franke, W W, Scheer, U, Spring, H, Trendelenburg, M F \& Zentgraf, H, The cell nucleus (ed H Busch) vol. 7, p. 49. Academic Press, New York (1979).

6. Miller, O L, Jr, J cell biol 91 (1981) 15.

7. Scheer, U \& Zentgraf, H, The cell nucleus (ed H Busch \& L Rothblum) vol. 11, p. 143. Academic Press, New York (1982).

8. Puvion-Dutilleul, F, Int rev cytol 84 (1983) 57.

9. Trendelenburg, M F, Hum genet 63 (1983) 197.

10. Fakan, S \& Puvion, E, Int rev cytol 65 (1980) 255.

11. Thiry, M, Lepoint, A \& Goessens, G, Biol cell 54 (1985) 57.

12. Mirre, C \& Stahl, A, J cell sci 48 (1981) 105.

13. Scheer, U \& Rose, K M, Proc natl acad sci US 81 (1984) 1431.

14. Granick, D, J cell biol 65 (1975) 389.

15. - Ibid 65 (1975) 418.

16. Scheer, U, Hügle, B, Hazan, R \& Rose, K M, J cell biol 99 (1984) 672.

17. Scheer, U, Trendelenburg, M F \& Franke, W W, J cell biol 65 (1975) 163.

18. Puvion-Dutilleul, F \& Bachellerie, J P, J ultrastruct res 66 (1979) 190.

19. Decker, K \& Keppler, D, Rev physiol biochem pharmacol 71 (1974) 77.

20. Keppler, D \& Holstege, A, Metabolic compartmentation (ed H Sies) p. 147. Academic Press, New York (1982).

21. Keppler, D, Rudiger, J, Bischoff, E \& Decker, K, Eur j biochem 17 (1970) 246.

22. Keppler, D, Pausch, J \& Decker, K, J biol chem 249 (1974) 211.

23. Gajdardjieva, K C, Dabeva, M D, Chelibonova-Lorer, H \& Hadjiolov, A A, FEBS lett 84 (1977) 48.

24. Shinozuka, H, Martin, J T \& Farber, J L, J ultrastruct res 44 (1973) 279.

25. Gajdardjieva, K C, Dabeva, M D \& Hadjiolov, A A, Eur j biochem 104 (1980) 451.

26. Dimova, R N, Gajdardjieva, K C, Dabeva, M D \& Hadjiolov, A A, Biol cell 35 (1979) 1.

27. Gajdardjieva, K C, Markov, D V, Dimova, R N, Kermekchiev, M B, Todorov, I T, Dabeva, M D \& Hadjiolov, A A, Exp cell res 140 (1982) 95.

28. Rose, K M, Stetler, D A \& Jacob, S T, Proc natl acad sci US 78 (1981) 2833.

29. Hügle, B, Hazan, R, Scheer, U \& Franke, W W, J cell biol 100 (1985) 873.

30. Dimova, R N, Markov, D V, Gajdardjieva, K C, Dabeva, M D \& Hadjiolov, A A, Eur j cell biol 28 (1982) 272.

31. Herzog, J \& Farber, J L, Exp cell res 93 (1975) 502.

32. Schmidt-Zachmann, M S, Hügle, B, Scheer, U \& Franke, W W, Exp cell res 153 (1984) 327.

33. Franke, W W, Kleinschmidt, J A, Spring, H, Krohne, G, Grund, C, Trendelenburg, M F, Stoehr, M \& Scheer, U, J cell biol 90 (1981) 289.

34. Krohne, G, Stick, R, Kleinschmidt, J A, Moll, R, Franke, W W \& Hausen, P, J cell biol 94 (1982) 749.

35. Benavente, R, Krohne, G, Stick, R \& Franke, W W, Exp cell res 151 (1984) 224.

36. Scheer, U, Messmer, K, Hazan, R, Raskas, I, Falk, H, Thomae, R, Hadjiolova, K \& Franke, W W. In preparation.

Received February 7, 1986 